Accepted for publication in Education Economics. Published online 6 May 2016. DOI

$\underline{10.1080 / 09645292.2016 .1182623}$

\title{
Determinants of Demand for Private Supplementary Tutoring in China: Findings from a National Survey
}

\author{
Junyan Liu and Mark Bray \\ Comparative Education Research Centre, The University of Hong Kong, China
}

Corresponding author: Junyan Liu, Tel: +852 63717457, E-mail address: liujy211@hku.hk

\begin{abstract}
Private tutoring has expanded and intensified in China. However, no government statistical data or other empirical studies fully capture its extent and characteristics. This paper analyses private tutoring received by students in Grades 1 to 12 as indicated by a nationwide representative survey entitled China Family Panel Studies (CFPS). The paper employs a Hurdle model to examine determinants of demand for tutoring, focusing on factors related to students and their parents. The first step is concerned with the decision to receive tutoring or not; and the second step explores factors influencing expenditures on tutoring among those who decide to receive it.
\end{abstract}

Key words: private tutoring, shadow education, demand, determinants, expenditure

\section{Introduction}

Private supplementary tutoring, widely known as shadow education because much of it mimics the curriculum of regular schooling, has become a global phenomenon alongside regular schooling (see e.g. Aurini, Davies, and Dierkes 2013; Mori and Baker 2010). In such countries as Japan and South Korea, tutoring has long been a vigorous activity and is deeply embedded in the culture (Bray 2009). Developments have been more recent in China, but private tutoring has 'caught up' with other countries through considerable expansion and intensification (Lei 2005; Tsang, Ding, and Shen 2010; 
Xue and Ding 2009).

No official statistics on private tutoring have been released in China, but a few empirical studies are available. Peking University’s 2004 Urban Household Education and Employment Survey indicated that $73.8 \%$ of students in primary education, $65.6 \%$ in junior secondary education, and 53.5\% in senior secondary education were receiving private tutoring (Xue and Ding 2009). However, this study only covered urban students. A 2006 survey conducted by Beijing Normal University in 18 locations found that $55.7 \%$ of urban families, $41.4 \%$ of county families and $22.8 \%$ of rural families paid for private tutoring (Chu 2009). However, this survey also had an urban bias; and since it covered only Grades 1-9, it did not provide information on senior secondary students. Other research has focused on private tutoring in limited geographic locations (e.g. Chen et al. 2012; Tsang, Ding, and Shen 2010; Zhang 2011; Zhang 2013).

The present paper analyses the private tutoring received by Chinese students in primary and secondary education (i.e. Grades 1 to 12 ) based on a nationwide representative sample in the China Family Panel Studies (CFPS). It investigates the factors underlying the demand for private tutoring, and specifically focuses on the demographic characteristics and personal perspectives of students and their parents. The authors recognise limitations insofar as peers, teachers and relatives may also influence the demand for private tutoring. Nevertheless, the paper adds to knowledge and understanding by presenting data and analysis on a major component in the education ecosystem (Bray \& Kobakhidze 2015). The Hurdle model is employed, with the first step analysing the factors underlying students' participation in private tutoring and the second step exploring the factors shaping expenditures on tutoring among those who decide to receive it.

\section{Context and Definitions}

\subsection{China's Educational Context}

Most parts of China have a " $6+3+3+4$ " education system, meaning six years of primary, three years of junior secondary, three years of senior secondary, and four years for a university degree. Schooling is compulsory for nine years, at the end of which students are selected for senior secondary schooling on the basis of their High School Entrance Examination (HSEE) results. Another assessment in Grade 12, the National College Entrance Examination (NCEE), is the main tool for university selection. Both primary and junior secondary schooling are almost universal, and the gross enrolment rate for senior secondary schooling was 82.5\% in 2010 (China MoE 2012).

During the last two decades, private tutoring has greatly expanded. Some students receive tutoring to catch up or keep up with their peers, while others receive tutoring for enrichment. In 
addition to academic tutoring, students receive support in sports, music, calligraphy, and other non-academic subjects. The students and their families may be motivated by personal interest and more rounded personal development, and/or they may desire extra credits in high-stakes examinations. The NCEE regulations set by the Beijing Municipal Education Commission have permitted students in the top groups of international or national sports competitions to gain an additional 20 points, which is a significant bonus (Qiu 2014). Authorities elsewhere in the country have different systems for awarding bonuses, but these benefits have widely encouraged primary and secondary students to seek tutoring for non-academic activities alongside academic ones.

\subsection{Definitions of Private Tutoring}

One common definition of private supplementary tutoring (see e.g. Bray 2009; Tan 2009) has three components:

- $\quad$ Privateness: tutoring provided in exchange for a fee - excluding unpaid tutoring provided by families, friends or community members, and extra tutoring provided by teachers free of charge as part of their professional responsibilities.

- Supplementation: tutoring in subjects taught in regular schooling but beyond the standard duties of the schools, and excluding instruction during the regular school day even if delivered by a private party.

- Academic: examinable subjects taught in schools, particularly languages and mathematics, and excluding domains such as music, art and sports.

However, to fit the Chinese context the definition of private tutoring in the present study is broader. It adopts the parameters of supplementation and privateness identified above, but includes non-academic as well as academic subjects on the grounds that they may also be seen as investments by families, particularly in view of the possibility of credits in high-stakes examinations.

\section{Literature on Determinants of Demand for Tutoring}

With the global expansion of private tutoring, a growing literature examines the elements underlying demand. Jokić (2013) brought a helpful conceptual advance by focusing on who makes decisions to receive (or not receive) private tutoring, and how. As he pointed out (p.26), such decisions are made almost exclusively by pupils and/or their parents, albeit perhaps with advice from peers, relatives, teachers and others. In line with this, the following summary of literature relates to both students and parents, and concerns factors in terms of both easily-measured demographic characteristics and 
personal perspectives.

Beginning with gender, in some countries parents who are economically constrained favour boys rather than girls. This is evident, for example, in Bangladesh, India and Pakistan (Aslam and Atherton 2014; Nath 2008). However, households in Hong Kong and South Korea seem commonly to favour girls over boys (Bray et al. 2014; Kim and Lee 2010). In China, empirical studies have not found consistent relationships between gender and private tutoring. Chu (2009) indicated that females had higher probability of receiving private tutoring, but Luo (2011) and Zhu (2012) found no significant influence of gender. This inconsistency may be partly explained by the researchers' samples in areas with different levels of economic development. Thus, broad geographic regions are also important. Studies showing considerable regional differences in the volume of private tutoring of both genders include Lei (2005), Shen (2008), and Xue and Ding (2009).

On a different dimension of location, researchers commonly find that rural students receive less private tutoring than their urban counterparts. Tutoring may be provided by teachers on a supplementary basis, and teachers are found in all locations. However, tutoring provided by commercial enterprises is concentrated in urban areas that have greater population densities and stronger capacity to pay for such services. Rural families may also be less inclined to seek tutoring because their communities and schools place less emphasis on competition. Higher tutorial enrolment rates among urban students have been demonstrated in South Korea (Kim and Lee 2010), Cambodia (Brehm and Silova 2014), Bangladesh (Nath 2008), Turkey (Tansel and Bircan 2006), and Kenya (Buchmann 2002).

Several studies in China have also noted urban/rural differences, but caution is needed in classification since urban/rural may be defined by hukou (household registration) as well as place of residence. The hukou system was designed to discourage migration, and limits the access that persons with rural registration have to government-provided services even if they are resident in towns (Hao, Hu, and Lo 2014). Concerning residence, several studies have found significant differences in demand for private tutoring among students in urban and rural areas (e.g. Chu 2009; Lei 2005; Zhou 2010). In addition, several studies have looked at the hukou status of students and have again found differences (e.g. Tsang, Ding, and Shen 2010; Zhang 2011; Zhang 2013).

Ethnicity and race may be another factor in the demand for tutoring, as noted for example in Malaysia, Sri Lanka and Singapore (Jelani and Tan 2012; Pallegedara 2012; Tan 2009). In China, minority ethnic groups not only have different cultural traditions but also have different levels of economic development which impact on education. The government identifies 56 ethnic groups, among which the Han comprise over $90 \%$ of the total population. Most ethnic minorities reside in sparsely populated regions with lower economic development (China SEAC 2009, 33-34). These 
families may face a dual disadvantage of poorer educational infrastructure and lower ability to afford the costs of schooling. Although educational disparities between Han and minorities have been reduced by reform in the financing of compulsory education (Tao 2008), disparities remain obvious in the domain of private tutoring (Zhang 2013, 123).

Students' level of education or grade is another relevant factor. In some societies, students in higher grades have higher probabilities of receiving tutoring (see e.g. Dang 2013, 103; Japan 2008, 13). In other societies, the pattern is opposite (see e.g. KOSIS 2013). Some studies in China have found more tutoring in lower grades (Chen et al. 2012; Chu 2009; Xue and Ding 2009). One factor lies in the availability of extra classes provided by schools free of charge. Some senior secondary schools ask students to stay late in the evening and also provide classes at the weekends. In such circumstances, students have less need and less time to seek private tutoring.

Turning to personal perspectives, a starting point concerns the educational expectations of both students and their parents. Higher educational aspirations may motivate students to study harder and generate demand for tutoring to gain additional help (Chu 2009; Liu 2012; Zhang 2013).

Demand for tutoring may also be associated with academic achievement measured by examination result or self-reported achievement. Lower achieving students may seek tutoring for remedial purposes, and higher achieving students may seek it for enrichment. However, the literature has not delivered consistent findings about the relationships between probability of tutoring and academic achievement (see e.g. Byun 2014; Liu 2012; Zhang 2013). Students' satisfaction about their academic achievement may have more direct relationship with demand for tutoring. Students who are satisfied with their achievement, even it is not high, may not seek tutoring, while students who are not satisfied with their achievement, even it is already high compared to peers, may seek tutoring to improve further. Students usually perceive a certain level of academic pressure in learning, and this pressure pushes some students to seek private tutoring (Zhang 2013). Especially in societies with high-stakes examinations, students may have strong academic pressure because of the potentially devastating consequences of failure (Kirss and Jokić 2013).

Students' or parents' dissatisfaction with school teachers' competence and/or ability to meet individual needs has been discussed in the literature as a possible factor contributing to the demand for tutoring (Kazimzade and Jokić 2013). It is assumed that students who are satisfied with their school teachers are less likely to receive help from external providers. However, patterns may be complex when teachers also provide private lessons: students who are satisfied with their teachers may have higher possibility to receive private tutoring from those teachers. Further, teacher's corruption, such as intentionally teaching less during school hours (Jayachandran 2014) or deliberately deflating students’ marks (Kobakhidze 2014), may coerce students to seek tutoring whether or not they 
are satisfied with their teachers.

As might be expected, household income has consistently been found to have a positive influence on the demand for private tutoring (Bray et al. 2014; Chu 2009; Ho and Kwong 2008). It is obvious that more prosperous families can afford greater amounts of tutoring than can poor families.

In general, parental educational level is also positively correlated. Students whose parents are highly educated are more likely to receive tutoring (Kim and Lee 2010; Xue and Ding 2009; Zhang 2013). Parents with higher educational levels are willing to invest more in children's education, including private tutoring.

\section{Research Focus and Methodology}

\subsection{Research Questions}

In the present study, the demand for private tutoring is measured by two variables: students' probability of receiving private tutoring during the previous year, and expenditures on private tutoring during the previous year. The paper addresses two questions:

1. What factors are associated with students' participation in private tutoring?

2. Having made the decision to take private tutoring, what factors shape expenditure on private tutoring?

The study focuses on factors associated with students and parents. It is important again to recognize the roles of other actors, including peers, relatives and teachers, even though they are beyond the scope of the present paper.

\subsection{Data Source}

The CFPS is a nationally representative, annual longitudinal survey of communities, families and individuals. It is funded by the Chinese government and managed by Peking University's Institute of Social Science Survey. The CFPS focuses on both economic and non-economic well-being, and includes data on education, family relations, migration, and physical and mental health. This paper draws on the baseline survey conducted in 2010.

Recognizing great regional differences, the CFPS baseline survey adopted three-stage PPS (Probability Proportional to Size) sampling with implicit stratification (Figure 1). The survey covered 19,986 households from 640 communities in 25 of Mainland China's 31 provinces and 
municipalities. ${ }^{1}$ The sampling strategy ensured that the CFPS represented $95 \%$ of the total population, and permits generalization of findings (Xie 2012).

[Figure 1 near here]

The CFPS baseline survey was conducted by 438 interviewers who were employed locally from the sampled areas. They completed six days of training in Peking University, and were closely supervised. Interviewers successfully covered 33,600 adults and 8,990 children below the age of 16 in 14,798 households from 635 communities in 25 designated provinces, providing a response rate of $81 \%$. The adult and child questionnaires both had sections on education, including questions about educational experiences, private tutoring, and academic performance.

The present study focuses on the private tutoring received by students from Grades 1 to 12, using a sub-sample of 6,009 students. The study uses this sub-sample to draw a picture of demand for private tutoring, which of course requires evidence that sub-sample is sufficiently large and representative. According to Seale (2012, 137), Simple Random Sampling (SRS) from this population would require a minimum sample of 2,401 students with a 0.02 margin of error and 95\% confidence level. However, the CFPS adopted stratified three-stage sampling, not SRS. It is necessary then to consider the precision gained or lost by the more complex design (Lohr 2009, 309). Table 1 presents the descriptive statistics of student sample.

\section{[Table 1 near here]}

For the present study, the design effect for the proportion of students receiving private tutoring was calculated to be 1.73 . This means that 1.73 times as many observations were needed with the design used in the CFPS baseline survey to obtain the same precision that would have been achieved with an SRS. Thus the minimum sample needed for the present paper was 4,154 students (multiplying the required sample size of 2,401 for SRS by the design effect of 1.73). That is to say, the sub-sample of 6,009 students derived from the CFPS sample using stratified three-stage sampling is large enough to be representative with a 0.02 margin of error and 95\% confidence level.

1 The excluded provinces were Hainan, Inner Mongolia, Ningxia, Qinghai, Xinjiang, and Xizang, all of which are relatively thinly populated. 


\subsection{Model}

To answer the first research question about the probability of students' participation in private tutoring, the most common method is Logit model regression, because the dependent variable is a dichotomous variable having values 0 and 1. For the second research question, the dependent variable is expenditure on private tutoring. Since only students who received private tutoring had positive expenditures, and students who did not receive tutoring spent zero, the dependent variable is censored at zero. In this case the Ordinary Least Squares (OLS) method, which has a premise of normal distribution, is not appropriate. Two models could be used to tackle the problem: the Tobit model and Hurdle model. In previous literature, both Tobit and Hurdle models have been used. For example Tansel and Bircan (2006) used a Tobit model to estimate the influence of family variables on tutoring expenditures in Turkey, while Kenayathulla (2012) used a Hurdle model to investigate the determinants of tutoring expenditures in Malaysia.

The Tobit model was proposed in 1958 to describe the relationship between a non-negative dependent variable $y_{i}$ and an independent variable (or vector) $x_{i}$ (Tobit 1958). As noted by McDonald and Moffit (1980, 318), a simple Tobit model can be written as:

$$
y_{i}= \begin{cases}y_{i}^{*} \text { if } y_{i}^{*}>0 \\ 0 \text { if } y_{i}^{*} \leq 0\end{cases}
$$

where $y_{i}^{*}$ is a latent variable $\mathrm{y}_{\mathrm{i}}^{*}=\beta \mathrm{x}_{\mathrm{i}}+\mathrm{u}_{\mathrm{i}}, \mathrm{u}_{\mathrm{i}} \sim N\left(0, \sigma^{2}\right)$

The Hurdle model proposed by Cragg (1971) and developed by Mullahy (1986) also has two steps. The first step is the binary outcome equation that models the probability of positive educational expenditures. The second step uses linear regression to model the decision of how much expenditure is incurred conditional on positive educational expenditures. As noted by Zhou and Li (2012, 106), a simple Hurdle model can be written as:

$$
\begin{aligned}
& I=x_{1} \alpha+u_{2}, \mathrm{u}_{2} \sim N(0,1) \\
& \operatorname{In}(y \mid \mathrm{I}>0)=\mathrm{x}_{2} \beta+u_{1}, E\left(\mathrm{u}_{1} \mid \mathrm{I}>0\right)=0 \\
& \mathrm{y}= \begin{cases}\mathrm{m}>0 & \text { if } \mathrm{I}>0 \\
0 & \text { if } \mathrm{I}<=0\end{cases}
\end{aligned}
$$

Statistically, the Hurdle model is an alternative to the Tobit model that does not require the assumptions of homoscedasticity and normality in order to achieve consistency (Cameron and 
Trivedi 2009). Conceptually, the difference between the Tobit and Hurdle models is whether the initial decision to take tutoring and the decision on how much to spend on tutoring are joint or separate. The Hurdle model enables the decision of whether to spend money on something to be modelled separately from the decision of how much to spend on it, conditional on positive expenditures.

Students and their parents usually make two separate decisions: i.e. first they have to decide whether to receive tutoring or not and then they have to decide how much to spend on tutoring. Psychological factors are the most important elements leading to participation in tutoring, such as expectations of educational attainment (Chu 2009), dissatisfaction with mainstream education (Kazimzade and Jokić 2013), and the perception of less attention in large classes (Zhang 2013). And when deciding how much to spend on tutoring, households have to consider budget constraints (Salvatore 2008). Economic resources then become the key determinants of expenditure, although psychological factors may remain influential. The Tobit model does not address this two-stage nature of choosing tutoring. The Hurdle model is more appropriate since the explanatory variables can have dissimilar effects on participation and expenditures on private tutoring.

The Hurdle model employed here has two steps. First, a binary logistic regression estimates the parameters of decision on participation in private tutoring [see equation (1)], and then a linear regression model estimates the parameters of decision on private tutoring expenditures [see equation (2)]. The variables are:

$$
\begin{aligned}
& \operatorname{Ln}\left[\frac{p_{i}}{1-p_{i}}\right]=a_{i}+\sum b_{i} \text { Indo }_{i}+\sum c_{i} I n d s_{i}+\sum d_{i} \operatorname{Par}_{i}+e_{i}(1) \\
& \operatorname{LnY}_{i}=a_{i}+\sum b_{i} \operatorname{Indo}_{i}+\sum c_{i} \operatorname{Inds}_{i}+\sum d_{i} \operatorname{Par}_{i}+u_{i}(2)
\end{aligned}
$$

- $\quad p_{\mathrm{i}}$ in equation (1) is the probability of student $\mathrm{i}$ receiving private tutoring during the previous year. Parents or guardians were asked how much they had spent on academic and non-academic tutoring for each child during the previous 12 months. This paper uses the data from this question to generate a variable indicating whether the child had received private tutoring. The variable was coded as 1 for positive expenditure, and 0 for no expenditure.

- $Y_{i}$ in equation (2) is the expenditure of student i's private tutoring during the previous year. Equation (2) uses the natural $\log$ of expenditure, i.e. $\operatorname{Ln} Y_{i}$, because like most expenditure data $Y_{i}$ is positively skewed while $\operatorname{Ln} Y_{i}$ has approximately normal distribution. 
- $\quad \sum I n d o_{i}$ is the set of student's demographic characteristics, including gender (dummy variable, female=0), hukou status (dummy variable, rural status=0), ethnicity (dummy variable, minority=0), region (two dummy variables, reference: Central region), and level of education (two dummy variables, reference: junior secondary education).

- $\quad \sum I n d s_{i}$ is the set of each students' personal perspectives, including four variables:

(a) Expected years of education: In the CFPS questionnaire, children were asked about their expectations about future educational levels with eight options: $1=$ not necessary to be educated, $2=$ primary education, $3=$ junior secondary education, $4=$ senior secondary education, 5= three-year college education, 6= Bachelor's degree, 7= Master's degree, $8=$ Doctor's degree. For the Hurdle model regression, the variable was recoded into “expected years of education” according to the years usually required to finish each level in the Chinese education system: not necessary to be educated $=0$, primary education $=6$, junior secondary education=9, senior secondary education=12, three-year college education=15, Bachelor's degree=16, Master's degree=19, Doctor's degree=22.

(b) Academic pressure: a variable measuring students' perceived academic pressure on a scale: $1=$ no pressure, $2=$ almost no pressure, $3=$ a little pressure, $4=$ =some pressure, $5=$ great pressure.

(c) Satisfaction about academic achievement: a variable measuring students' satisfaction about their academic achievement on a scale: $1=$ very dissatisfied, $2=$ dissatisfied, $3=$ neither dissatisfied nor satisfied, $4=$ satisfied, $5=$ very satisfied.

(d) Satisfaction about school teacher: Children were asked to evaluate their Chinese, Mathematics and English teachers with five options for each: 1= very dissatisfied, 2= dissatisfied, $3=$ neither dissatisfied nor satisfied, $4=$ satisfied, $5=$ very satisfied. For the Hurdle model regression, factor analysis was used to combine these three variables into the one variable "satisfaction about school teacher".

- $\quad \sum \operatorname{Par}_{i}$ is the set of parental factors, including two variables:

(a) Natural log of annual household income per capita.

(b) Parental years of education: the years of education of the parent with the higher level of education. 


\section{Findings and Data Analysis}

The CFPS baseline survey indicated that $24.2 \%$ of sampled students had received private tutoring during the previous year while $75.8 \%$ had not. Among the students who had received tutoring, the average annual expenditure was CNY1,290 (US\$210). Table 2 further reports these descriptive statistics among different groups of students.

[Table 2 near here]

The following sections analyze the determinants of probability of receiving private tutoring through binary logistic regression (Table 3, Step 1) in the Hurdle model, and investigate the determinants of expenditure through conditional linear regression (Table 3, Step 2). In addition to the Hurdle model results, Table 3 reports the Tobit model results regarding the determinants of expenditure for reference.

[Table 3 near here]

\subsection{Determinants of Probability of Receiving Private Tutoring}

\subsubsection{Students’ Demographic Characteristics}

From the descriptive statistics, the difference of participation rates in private tutoring between males and females seemed negligible (Table 2). The logistic regression confirmed that gender had no significant relationship with the probability of receiving tutoring. As noted above, in some countries boys are commonly the priority for family investments both within and outside schools. Due to the one-child policy, most Chinese families have just one child, which means that parents concentrate on that child whether male or female. Even among families with more than one child, this study did not identify significant gender differences. This finding was consistent with other research (e.g. Zhu 2012; Zhang 2013).

The probability of receiving private tutoring did vary according to students' hukou status (Table 2). After controlling for other variables listed in Table 3, the likelihood of urban hukou students receiving tutoring was $\mathbf{8 6 . 4 \%}$ higher than for rural hukou students. The pattern of differentiated demand between urban hukou and rural hukou students is unique to China because of the special hukou system. The urban/rural stratification caused by the hukou system gives rise to inequality not only in mainstream education (Hao, Hu, and Lo 2014) but also in private tutoring.

Consistent with previous studies (e.g. Dang 2007; Zhang 2013), majority students enjoy the 
higher probability of receiving private tutoring: the likelihood for Han students to take private tutoring was 96.9\% higher than for minority students (Table 3).

The logistic regression did not show a significant regional difference in the participation rates of private tutoring when controlling for other variables. Under the administrative system of "local responsibility”, uneven economic development causes educational disparities among regions (Zhai \& Sun, 2012). Nevertheless, parents appear to feel a need to invest in private tutoring regardless of this diversity.

Students' levels of education were not found to have significant influence on the probability of receiving private tutoring. As noted, in this study the tutoring includes both academic and non-academic subjects. Primary students may have less need for tutoring in academic subjects than junior secondary students, but they may have more time for non-academic subjects. Senior secondary students have less time for tutoring due to the intense school schedules, but they are under more examination pressure.

In addition, the present paper incorporated the interaction terms into the model and found no significant interaction between student's gender and current education levels. However, the interaction between hukou status and current education level was significant: the difference of demand for tutoring between rural and urban hukou status existed for students at primary and secondary education, and among them urban hukou primary students had especially higher probability of receiving tutoring. Besides the difference in participation in academic tutoring, urban hukou parents of primary students are more enthusiastic to send children for non-academic tutoring to cultivate and develop their interests (Li 2009; Zhou 2010).

\subsubsection{Students'Personal Perspectives}

Among the four variables for students' personal perspectives, the hypotheses in terms of positive influence of educational expectation and negative influence of satisfaction about academic achievement were confirmed by the logistic regression. When students' expected years of education increased by 1.0 , the probability of receiving private tutoring increased by $4.3 \%$. When students' satisfaction about academic achievement increased by 1.0, the likelihood of receiving tutoring decreased by $10.8 \%$ (Table 3 ).

Students who perceived more academic pressure were hypothesized to be more likely to seek private tutoring. The logistic regression showed a positive influence, but it was not statistically significant. Perceived academic pressure was thus not a strong indicator of participation in tutoring.

A further question concerned the relationship between students' satisfaction about school 
teachers and their demand for tutoring. The logistic regression did not show a clear pattern: the positive coefficient of the variable "satisfaction about school teachers" was not statistically significant. This insignificance may be partly due to the evident regional differences in China. In most rural areas, the limited opportunities for private tutoring may constrain the demand for tutoring, no matter whether students are satisfied with teachers or not. In addition, although the Chinese government prohibits teachers from tutoring their regular students on a fee-paying basis, the extent to which this rule is enforced varies (Kwok 2010). When teachers also serve as tutors, their possible corruption may push students to receive tutoring, no matter the level of students' satisfaction with the teachers. Without deeper understanding of teacher's behaviour and students' and/or parents' decision-making processes about seeking tutoring, the relationship between students' satisfaction with school teachers and the demand for tutoring is difficult to identify. It remains a question for further study, especially through qualitative research.

\subsubsection{Parental Factors}

Consistent with other empirical studies (Bray et al. 2014; Chu 2009; Ho and Kwong 2008; Xue and Ding 2009; Zhang 2013), both household income and parental educational level had significantly positive influence on the probability of receiving private tutoring. When the natural log of annual household income per capita increased by 1.0, the probability of receiving private tutoring increased by $29.9 \%$. When parental years of education increased by 1.0 , the likelihood of participation in private tutoring increased by $8.2 \%$ (Table 3 ).

\subsection{Determinants of Expenditure on Private Tutoring}

With the same independent variables from step 1, step 2 of the Hurdle model examined the determinants of expenditure on private tutoring on condition that the decision to receive tutoring had been made. Only students with positive private tutoring expenditures were included in the analysis of step 2 (Table 3).

Firstly, among the students' demographic characteristics, hukou status was a significantly positive indicator for expenditure on private tutoring. Although minority students were less likely to receive tutoring, they spent significantly more on tutoring once they decided to take it. The probability of receiving tutoring did not vary across regions, but the expenditures were different: students in Western China spent significantly less on tutoring than their counterparts in Central China. Expenditures did not vary significantly among students with different education levels.

Secondly, among the students' personal perspectives, educational expectations predicted more expenditure on private tutoring. Although students' satisfaction about their academic achievement 
was negatively correlated with the probability of receiving tutoring, it had a significantly positive influence on expenditures. Students who were satisfied with their academic achievement had less demand for tutoring, but if they still decided to take tutoring for further progress they were likely to spend more. The other two factors of perspective, students' perceived academic pressure and students’ satisfaction with teachers, had no significant influence on expenditure.

Thirdly, household income and parental years of education also had significantly positive influence on the expenditure on private tutoring.

\section{Conclusions}

Although increasing numbers of Chinese students are receiving private tutoring, neither official data nor independent studies have fully assessed the phenomenon. Based on a nationwide representative sample in the 2010 CFPS baseline survey, the present paper contributes to the picture. It investigates not only the probability of receiving tutoring but also expenditures on tutoring. It also sheds light on determinants, focusing on students and parents.

The finding of no significant gender difference in demand for private tutoring matches much of the wider literature. When household resources were limited and labour markets differentiated the returns to education in a manner privileging boys, parents would have a reason to favour boys in educational investment (Lee 2004). With economic development, perceptions of gender differences in labour market opportunities may lessen and gender disparities in education would decrease. The one-child policy further encourages parents to treat boys and girls equally in educational investment, including private tutoring.

The pattern of differentiated demand between students with urban or rural hukou status is not just a matter of limited opportunities in rural areas: the parents with rural hukou status in urban areas commonly had lower incomes and thus could not easily afford private tutoring. Rural hukou students had lower probabilities of receiving private tutoring than urban hukou students, which placed rural hukou students in a further disadvantaged situation.

The findings about the influence of household income and parental educational level on demand for private tutoring are consistent with the existing literature. These two factors were positively correlated with the probability and expenditures on private tutoring.

Most previous studies about private tutoring in China have only investigated the demographic characteristics. The present study took a step further to test the influence of some personal perspectives on the demand for private tutoring. It reveals that students' expectations about future educational levels have significantly positive influence on the probability of receiving private 
tutoring. Students who are dissatisfied with their academic achievement are more likely to seek help from private tutoring. Although having less demand for private tutoring, students who are already satisfied with their academic achievement are likely to spend more for tutoring if they do decide to seek tutoring.

These patterns of demand indicate that private tutoring may have negative influence on equity. Students with Han ethnicity and/or urban hukou status may have additional opportunities to learn, or may enjoy additional educational resources in the process of tutoring. Further, students from wealthier families are more likely to receive tutoring and to spend more on it than students from lower-income families. These patterns show the importance of policymakers addressing the phenomenon.

At the same time, this study is limited in several ways. First, it does not investigate the influence of parents' perspectives on demand for tutoring even though parents play an important role in decisions about whether to seek tutoring and then how much money to spend on it. Second, data for the paper are from a complex dataset containing much information on different domains. Since it was not designed to focus solely on private tutoring, the data are limited in scope. A more detailed survey focusing specifically on private tutoring would resolve this problem.

Acknowledgements: The data used in this paper are from the China Family Panel Studies (CFPS), funded by the 985 Program of Peking University and carried out by the Institute for Social Science Survey of Peking University. We sincerely thank the CFPS team in Peking University for sharing the data.

\section{References}

Aslam, M., and Atherton, P. 2014. “The 'Shadow' Education Sector in India and Pakistan: Opening Pandora's box.” In Education, Privatisation and Social Justice: Case Studies from Africa, South Asia and South East Asia, edited by Macpherson, I., Robertson, S., and Walford, G.,137-158. Oxford: Symposium.

Aurini, J., Davies, S., \& Dierkes, J. 2013. "Out of the Shadows? An Introduction to Worldwide Supplementary Education.” In Out of the Shadows: The Global Intensification of Supplementary Education, edited by Aurini, J., Davies, S., and Dierkes, J., xv-xxiv. Bingley: Emerald.

Bray, M. 2009. Confronting the Shadow Education System: What Government Policies for What Private Tutoring?. Paris: UNESCO International Institute for Educational Planning.

Bray, M., Zhan, S., Lykins, C., Wang, D., and Kwo, O. 2014. "Differentiated Demand for Private Supplementary Tutoring: Patterns and Implications in Hong Kong Secondary Education." Economics of Education Review, 38(1): 24-37.

Bray, M., and Kobakhidze, M.N. 2015. "Evolving Ecosystems in Education: The Nature and Implications of Private Supplementary Tutoring in Hong Kong.” Prospects: Quarterly Review of Education. DOI: 10.1007/s11125-015-9353-2. 
Brehm, W., and Silova, I. 2014. "Ethical Dilemmas in the Education Marketplace: Shadow Education, Political Philosophy and Social (In)Justice in Cambodia.” In Education, Privatisation and Social Justice: Case Studies from Africa, South Asia and South East Asia, edited by Macpherson, I., Robertson, S., and Walford, G., 159-178. Oxford: Symposium.

Buchmann, C. 2002. "Getting Ahead in Kenya: Social Sapital, Shadow Education, and Achievement." In Schooling and Social Capital in Diverse Cultures, edited by Fuller, B. and Hannum, E., 133-159. Amsterdam: JAI Press.

Byun, S.Y. 2014. "Shadow Education and Academic Success in the Republic Of Korea.” In Korean Education in Changing Economic and Demographic Contexts, edited by Park, H., and Kim, K.K., 39-58. Dordrecht: Springer.

Cameron, A., and Trivedi, P. 2009. Microeconometrics Using Stata. College Station, Texas: Stata Press.

Chen, L., Su, S., Pang, Y. and Chen, J. 2012. “The Influential Factors of Private Mathematics Tutoring of Elementary and Secondary Students in Beijing.” Journal of Educational Studies, 8(1): 67-73. [in Chinese]

China, MoE (Ministry of Education) 2012. Statistical Bulletin of Chinese Educational Development in 2010. [in Chinese.] Ministry of Education. Accessed 26 June 2014. http://www.moe.edu.cn/publicfiles/business/htmlfiles/moe/moe_633/201308/155798.html

China, SEAC (State Ethnic Affairs Commission) 2009. Ethnic Affairs in China. [in Chinese.] Beijing: Ethnic Affairs Publishing House.

Chu, H. 2009. "The Impact of Family Background and Personal Characteristics on the Participation in Supplementary Education in China.” [in Chinese.] Education Research Monthly, 12: 22-27.

Cragg, J. G. 1971. "Some Statistical Models for Limited Dependent Variables with Application to the Demand for Durable Goods.” Econometrica, 39(5): 829-844.

Dang, H.A. 2007. "The Determinants and Impact of Private Tutoring Classes in Vietnam." Economics of Education Review, 26(6), 684-699.

Dang, H.A. 2013. "Private Tutoring in Vietnam: A Review of Current Issues and Its Major Correlates." in Out of the Shadows: The Global Intensification of Supplementary Education, edited by Aurini, J., Davies, S. and Dierkes, J., 95-128. Bingley: Emerald.

Hao, L., Hu, A. and Lo, J. 2014. "Two Aspects of the Rural-Urban Divide and Educational Stratification in China: A Trajectory Analysis.” Comparative Education Review, 58(3), 509-536.

Ho, E.S.C., and Kwong, W.L. 2008. Shadow Education and Related Services in Macao: The Phenomenon and its Impact. [in Chinese.] Hong Kong: Hong Kong Centre for International Student Assessment.

Japan, Ministry of Education and Training 2008. Report on the Situation of Academic Learning Activities of Children. [in Japanese.] Tokyo: Monbukagakusho Hokokusho.

Jayachandran S. 2014. "Incentives to teach badly: After-school tutoring in developing countries". Journal of Development Economics, 108, 190-205

Jelani, J., and Tan, A.K.G. 2012. "Determinants of Participation and Expenditure Patterns of Private Tuition Received by Primary School Students in Penang, Malaysia: An Exploratory Study.” Asia 
Pacific Journal of Education, 32(1), 19-35.

Jokić, B. (ed.) 2013. Emerging from the Shadow: A Comparative Qualitative Exploration of Private Tutoring in Eurasia. Zagreb: Network of Education Policy Centers.

Kazimzade, E., and Jokić, B. 2013. "The Roles of Parents in the Decision Concerning the Use of Private Tutoring”. In B. Jokić (Ed.), Emerging from the Shadow: A Comparative Qualitative Exploration of Private Tutoring in Eurasia. Zagreb: Network of Education Policy Centers, pp.209-238.

Kenayathulla, H.B. 2012. “An Economic Analysis of Household Educational Decisions in Malaysia.” PhD diss., Indiana University.

Kim, S., and Lee, J. 2010. "Private Tutoring and Demand for Education in South Korea.” Economic Development and Cultural Change, 58(2), 259-296.

Kirss, L., and Jokić B. 2013. "Individual Pupil Characteristics and the Decisions Concerning Private Tutoring Use”. In B. Jokić (Ed.), Emerging from the Shadow: A Comparative Qualitative Exploration of Private Tutoring in Eurasia. Zagreb: Network of Education Policy Centers, pp.163-207.

Kobakhidze, M.N. 2014. “Corruption risks of private tutoring: case of Georgia.” Asia Pacific Journal of Education, 34:4, 455-475.

KOSIS (Korean Statistical Information Service) 2013. "Private Education Participation Rate by School Level.” KOSIS. Accessed 20 Nov. 2014. http://kosis.kr/nsieng/view/stat10.do

Kwok, P.L.Y. 2010. "Demand Intensity, Market Parameters and Policy Responses towards Demand and Supply of Private Supplementary Tutoring in China.” Asia Pacific Education Review, 11(1): 49-58.

Lee, W.O. 2004. Equity and Access to Education: Themes, Tensions, and Policies. Manila: Asian Development Bank.

Lei, W. 2005. "Expenditure on Private Tutoring for Senior Secondary Students: Determinants and Policy Implications.” [in Chinese.] Education and Economics, 1:39-42.

Li, L. 2009. “An empirical study on household educational investment in Shanghai.” [in Chinese.] Master thesis, Fudan University.

Liu, J. 2012. "Does Cram Schooling Matter? Who Goes to Cram Schools? Evidence from Taiwan.” International Journal of Educational Development, 32(1), 46-52.

Lohr, S. 2009. Sampling: Design and Analysis. Boston: Cengage Learning.

Luo 2011. "Investigation on the Private Tutoring of Primary Students.” [in Chinese.]Master thesis, Nanjing Normal University.

McDonald, J. and Moffit, R. 1980. "The Uses of Tobit Analysis.” The Review of Economics and Statistics, 62(2): 318-321.

Mori, I., and Baker, D. 2010. "The Origin of Universal Shadow Education: What the Supplemental Education Phenomenon Tells Us about the Postmodern Institution of Education.” Asia Pacific Education Review, 11(1): 36-48.

Mullahy, J. 1986. “Specification and Testing of Some Modified Count Data Models.” Journal of Econometrics, 33(3): 341-365.

Nath, S. 2008. "Private Supplementary Tutoring among Primary Students in Bangladesh." Educational Studies, 34(1): 55-72. 
Pallegedara, A. 2012. "Demand for Private Tutoring in a Free Education Country: The Case of Sri Lanka”. International Journal of Education Economics and Development, 3(4): 375-393.

Qiu, Q. 2014. "Beijing Will Implement the New Bonus-Point System for National College Entrance Examination: Six Types of Students Could Get Additional 20 Points.” [in Chinese.] Beijing Examinations, 26 Mar. www.bjeea.cn/

Salvatore, D. 2008. Microeconomics: theory and applications. New York: Oxford University Press.

Seale, C. (ed.) 2004. Researching Society and Culture. London: Sage Publications Ltd.

Shen, H. 2008. "An Investigation on Factors Influencing Private Supplementary Tutoring at the Level of Compulsory Education.” [in Chinese.] Economics of Education Research, 6(3): 1-10.

Tan, J. 2009. "Private Tutoring in Singapore: Bursting out of the Shadows". Journal of Youth Studies, 12(1): 93-103.

Tansel, A., and Bircan, F. 2006. "Demand for Education in Turkey: A Tobit Analysis of Private Tutoring Expenditures. ”Economics of Education Review, 25(3): 303-313.

Tao, X. 2008. "Major Policy Promoting Educational Equity in China.” [in Chinese] Guangming Daily, 3 Nov. http://www.gmw.cn/01gmrb/2008-09/03/content_831618.htm.

Tobit, J. 1958. “Estimation of Relationships for Limited Dependent Variables”. Econometrica, 26(1): 24-36.

Tsang, M., Ding, X., and Shen, H. 2010. "Urban-Rural Disparities in Private Tutoring of Lower Secondary Students.” [in Chinese.]Education and Economics, 2: 7-11.

Xie, Y. 2012. The User's Guide to the China Family Panel Studies in 2010. [in Chinese.] Beijing: Institute of Social Science Survey, Peking University.

Xue, H., and Ding, X. 2009. “An Empirical Study on Private Tutoring for Students in Urban China.” [in Chinese.] Economics of Education Research, 6(1): 1-14.

Zhai, B. and Sun, B. 2012. "Investigation of Uneven Development of Basic Education in China.” [in Chinese.] China Education Newspaper, 2 July.

Zhang, Y. 2011. "The Determinants of National College Entrance Exam Performance in China - With an Analysis of Private Tutoring.” PhD diss., Columbia University.

Zhang, W. 2013. "Private Supplementary Tutoring Received by Grade 9 Students in Chongqing, China: Determinants of Demand, and Policy Implications.”. PhD diss., The University of Hong Kong.

Zhou, H. and Li, X. 2012. "Estimation Method and Application of Tobit Model.” [in Chinese.] Economic Perspectives, (5): 105-119.

Zhou, L. 2010. "Extra-curricular Training Consumption of Compulsory Education Students: A Survey of Four Schools in Urban/Rural Areas in Wucheng District, Jinhua.” [in Chinese.] Master thesis, Zhejiang Normal University.

Zhu, Y. 2012. “An Empirical Study of Family Alternative Education Consumption of Compulsory Education in a Rural Area: Wuyuan, Jiangxi.” [in Chinese.] Master thesis, Jiangxi Normal University. 
Table 1: Descriptive statistics of student sample

\begin{tabular}{|c|c|c|c|c|c|}
\hline Characteristics & $\mathbf{N}$ & $\%$ & Characteristics & $\mathbf{N}$ & $\%$ \\
\hline \multicolumn{3}{|l|}{ Gender } & \multicolumn{3}{|l|}{ Region } \\
\hline Male & 3,114 & 51.8 & Eastern & 2,298 & 38.2 \\
\hline Female & 2,895 & 48.2 & Central & 1,841 & 30.6 \\
\hline \multicolumn{3}{|l|}{ Ethnicity } & Western & 1,870 & 31.1 \\
\hline Han & 5,383 & 89.6 & \multicolumn{3}{|l|}{ Level of education } \\
\hline Minority & 604 & 10.1 & Primary & 3,541 & 58.9 \\
\hline Missing & 22 & 0.4 & Junior secondary & 1,555 & 25.9 \\
\hline \multicolumn{3}{|l|}{ Hukou status } & Senior secondary & 913 & 15.2 \\
\hline Urban hukou & 1,294 & 21.5 & \multirow{3}{*}{ Total Cases } & \multirow{3}{*}{6,009} & \multirow{3}{*}{100.0} \\
\hline Rural hukou & 4,709 & 78.4 & & & \\
\hline Missing & 6 & 0.1 & & & \\
\hline
\end{tabular}

Table 2: Descriptive statistics about probability and expenditures on private tutoring

\begin{tabular}{|c|c|c|c|}
\hline & & $\begin{array}{l}\text { Probability of } \\
\text { receiving private } \\
\text { tutoring (\%) }\end{array}$ & $\begin{array}{c}\text { Average } \\
\text { expenditure on } \\
\text { private tutoring } \\
\text { (CNY) }\end{array}$ \\
\hline & Whole sample & 24.2 & 1,290 \\
\hline \multirow{2}{*}{ Gender } & Male & 24.8 & 1,279 \\
\hline & Female & 23.4 & 1,303 \\
\hline \multirow{2}{*}{ Hukou status } & Urban & 46.8 & 1,997 \\
\hline & Rural & 16.9 & 664 \\
\hline \multirow{2}{*}{ Ethnicity } & Han & 25.8 & 1,307 \\
\hline & Minority & 13.0 & 1,133 \\
\hline \multirow{3}{*}{ Region } & Eastern & 24.1 & 1,405 \\
\hline & Central & 28.6 & 1,551 \\
\hline & Western & 18.5 & 567 \\
\hline \multirow{3}{*}{$\begin{array}{l}\text { Level of } \\
\text { Education }\end{array}$} & Primary education & 22.5 & 1,283 \\
\hline & Junior secondary education & 25.3 & 1,188 \\
\hline & Senior secondary education & 26.9 & 1,415 \\
\hline
\end{tabular}

* Annual expenditure on private tutoring for one child during the previous 12 months. Selects only cases with have positive expenditure on private tutoring when calculating the mean. One yuan (CNY) was equivalent to approximately US\$0.15. 
Table 3: Model results about determinants of probability and expenditure for private tutoring ${ }^{\boldsymbol{b}}$

\begin{tabular}{|c|c|c|c|c|c|c|c|}
\hline \multirow{4}{*}{ Independent Variables } & \multicolumn{5}{|c|}{ Hurdle model } & \multirow{3}{*}{\multicolumn{2}{|c|}{$\begin{array}{c}\text { Tobit model } \\
\text { Ln (private } \\
\text { tutoring } \\
\text { expenditure) }\end{array}$}} \\
\hline & \multirow{2}{*}{\multicolumn{3}{|c|}{$\begin{array}{c}\text { Step } 1^{\mathrm{a}} \\
\begin{array}{c}\text { Probability of receiving private } \\
\text { tutoring }\end{array}\end{array}$}} & \multirow{2}{*}{\multicolumn{2}{|c|}{$\begin{array}{c}\text { Step } 2^{\mathrm{a}} \\
\begin{array}{l}\text { Ln (private tutoring } \\
\text { expenditure) }\end{array}\end{array}$}} & & \\
\hline & & & & & & & \\
\hline & Coef. & $\begin{array}{c}\text { Robust } \\
\text { S.E. }\end{array}$ & $\begin{array}{l}\text { Odds } \\
\text { Ratio }\end{array}$ & Coef. & $\begin{array}{c}\text { Robust } \\
\text { S.E. }\end{array}$ & Coef. & $\begin{array}{c}\text { Robust } \\
\text { S.E. }\end{array}$ \\
\hline \multicolumn{8}{|l|}{ Student's factors } \\
\hline \multicolumn{8}{|l|}{ Demographic characteristics } \\
\hline Gender (Female $=0)$ & .073 & .216 & 1.075 & -.262 & .216 & -.003 & .165 \\
\hline Hukou Status (Rural=0) & $.623^{\star \star \star}$ & .223 & $1.864^{\star \star \star}$ & $.496^{\star \star}$ & .242 & $.548^{\star \star \star}$ & .175 \\
\hline Ethnicity (Minority=0) & $.677^{\star \star \star}$ & .243 & $1.969^{\star \star \star}$ & $-.367^{\star \star}$ & .178 & $-.304^{\star}$ & .174 \\
\hline \multicolumn{8}{|l|}{ Region (Reference: Central region) } \\
\hline Eastern region & -.181 & .120 & 0.834 & -.133 & .117 & .004 & .097 \\
\hline Western region & .215 & .162 & 1.240 & $-.745^{\star \star \star}$ & .180 & $-.729^{\star \star \star}$ & .118 \\
\hline \multicolumn{8}{|c|}{ Educational level(Reference: Junior secondary) } \\
\hline Primary & -.171 & .199 & 0.842 & -.021 & .185 & .017 & .159 \\
\hline Senior secondary & -.125 & .222 & 0.882 & .344 & .221 & $.374^{\star \star}$ & .178 \\
\hline \multicolumn{8}{|c|}{ Gender * Educational level (Reference: Female junior secondary students) $^{c}$} \\
\hline Male primary & .037 & .280 & 1.038 & .076 & .271 & -.197 & .210 \\
\hline Male junior secondary & .001 & .272 & 1.001 & .237 & .262 & -.012 & .210 \\
\hline \multicolumn{8}{|c|}{ Hukou status * Educational level (Reference: Rural junior secondary students) ${ }^{d}$} \\
\hline Urban primary & $.664^{\star \star}$ & .288 & $1.942^{\star \star}$ & .200 & .280 & .313 & .212 \\
\hline Urban junior secondary & -.011 & .284 & 0.989 & .137 & .269 & .235 & .214 \\
\hline \multicolumn{8}{|l|}{ Personal perspectives } \\
\hline Expected years of education & $.042^{\star \star}$ & .018 & $1.043^{* *}$ & $.054^{\star \star \star}$ & .020 & $.063^{\star \star \star}$ & .015 \\
\hline Academic pressure & .068 & .049 & 1.071 & .037 & .047 & .051 & .038 \\
\hline Satisfaction about academic achievement & $-.114^{\star}$ & .066 & $0.892^{*}$ & $.100^{*}$ & .057 & .027 & .047 \\
\hline Satisfaction about school teacher & .071 & .059 & 1.073 & .059 & .058 & .028 & .043 \\
\hline \multicolumn{8}{|l|}{ Parental factors } \\
\hline Ln (annual household income per capita) & $.262^{\star \star \star}$ & .070 & $1.299^{\star \star \star}$ & $.234^{\star \star \star}$ & .069 & $.213^{\star \star \star}$ & .038 \\
\hline Parental years of education & $.079^{\star \star \star}$ & .017 & $1.082^{\star \star \star}$ & $.080^{\star \star \star}$ & .016 & $.082^{\star \star \star}$ & .013 \\
\hline Pseudo $R^{2} / R^{2}$ & \multicolumn{3}{|c|}{0.105} & \multicolumn{2}{|c|}{0.329} & \multicolumn{2}{|c|}{0.131} \\
\hline Chi-square / F & \multicolumn{3}{|c|}{ 202.99*** } & \multicolumn{2}{|c|}{$21.81 * * *$} & \multicolumn{2}{|c|}{$454.07 * * *$} \\
\hline
\end{tabular}

a. The Hurdle Model includes a logistic regression (step 1) and a conditional linear OLS regression (step 2), selecting only cases which have positive expenditure on private tutoring.

b. Both the logistic regression and conditional linear regression use the sampling weight of each observation.

c. The interaction terms "Female primary", "Female senior secondary" and "Male senior secondary" are omitted because of collinearity.

d. The interaction terms "Rural primary", "Rural senior secondary" and "Urban senior secondary" are omitted because of collinearity.

$* \mathrm{p}<0.1 .{ }^{* *} \mathrm{p}<0.05 . * * * \mathrm{p}<0.01$. 
Figure 1: Flow Chart of Sampling and Data Collection of CFPS Baseline Survey

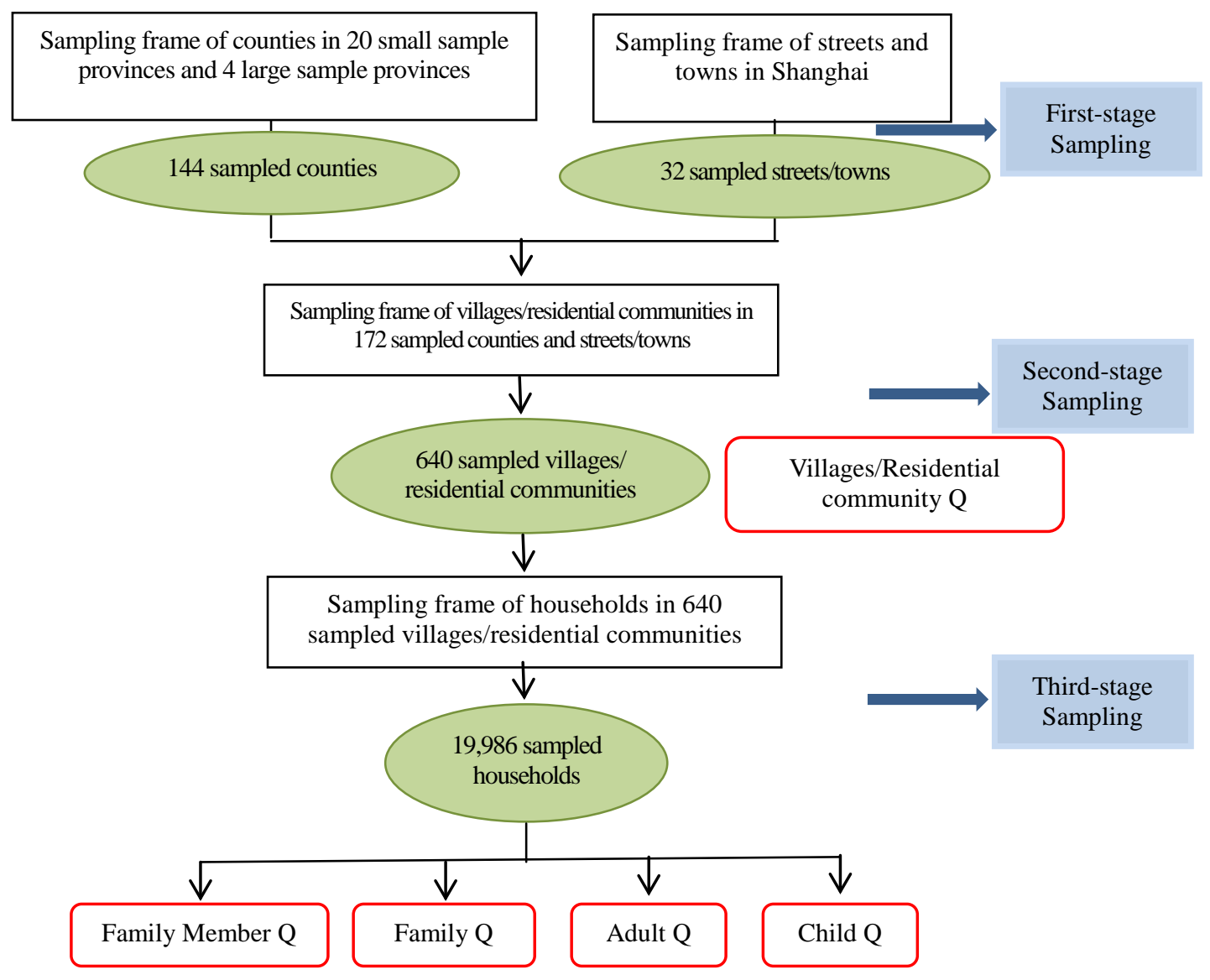

